\title{
Effects of interfacial residual stress on mechanical behavior of $\mathrm{SiC}_{\mathrm{f}} / \mathrm{SiC}$ composites
}

\author{
Xiaowu $\mathrm{CHEN}^{a, b, *}$, Guofeng $\mathrm{CHENG}^{c}$, Jinshan $\mathrm{YANG}^{a, b}$, Jianbao $\mathrm{HU}^{a, b}$, \\ Chunjin LIAO ${ }^{a, b}$, Xiangyu ZHANG ${ }^{a, b}$, Shaoming $\mathrm{DONG}^{a, b, *}$ \\ ${ }^{a}$ State Key Laboratory of High Performance Ceramics and Superfine Microstructure, \\ Shanghai Institute of Ceramics, Chinese Academy of Sciences, Shanghai 200050, China \\ ${ }^{b}$ Structural Ceramics and Composites Engineering Research Center, Shanghai Institute of Ceramics, \\ Chinese Academy of Sciences, Shanghai 200050, China \\ ${ }^{c}$ Analysis and Testing Center for Inorganic Materials, Shanghai Institute of Ceramics, \\ Chinese Academy of Sciences, Shanghai 200050, China
}

Received: March 21, 2021; Revised: June 13, 2021; Accepted: July 8, 2021

(c) The Author(s) 2021.

\begin{abstract}
Layer-structured interphase, existing between reinforcing fiber and ceramics matrix, is an indispensable constituent for fiber-reinforced ceramic composites due to its determinant role in the mechanical behavior of the composites. However, the interphase may suffer high residual stress because of the mismatch of thermal expansion coefficients in the constituents, and this can exert significant influence on the mechanical behavior of the composites. Here, the residual stress in the boron nitride $(\mathrm{BN})$ interphase of continuous $\mathrm{SiC}$ fiber-reinforced $\mathrm{SiC}$ composites was measured using a micro-Raman spectrometer. The effects of the residual stress on the mechanical behavior of the composites were investigated by correlating the residual stress with the mechanical properties of the composites. The results indicate that the residual stress increases from 26.5 to $82.6 \mathrm{MPa}$ in tension as the fabrication temperature of the composites rises from 1500 to $1650{ }^{\circ} \mathrm{C}$. Moreover, the increasing tensile residual stress leads to significant variation of tensile strain, tensile strength, and fiber/matrix debonding mode of the composites. The sublayer slipping of the interphase caused by the residual stress should be responsible for the transformation of the mechanical behavior. This work can offer important guidance for residual stress adjustment in fiber-reinforced ceramic composites.
\end{abstract}

Keywords: ceramic matrix composites; Raman spectroscopy; mechanical properties; residual stress

\section{Introduction}

Continuous fiber-reinforced ceramic matrix composites

* Corresponding authors.

E-mail: X. Chen, xwchen@mail.sic.ac.cn; S. Dong, smdong@mail.sic.ac.cn
(CFCMCs) are promising materials for replacing some nickel-base super-alloys in hot section components of advanced aero-engines [1,2]. CFCMCs are mainly composed of reinforcing fiber, ceramic matrix, and layer-structured interphase between them. The multiple constituents endow CFCMCs with much more favorable mechanical characteristics over conventional ceramics, such as high damage tolerance to cracks and non-brittle 
fracture $[3,4]$. These favorable mechanical characteristics combined with other advantages, such as low density and high temperature corrosion/oxidation stability, enable aero-engines to operate with increasing efficiency and reducing emissions [5].

Among the multiple constituents, an elaborately tailored interphase is a prerequisite to obtain CFCMCs with optimized mechanical properties [6,7]. So far, layer-structured pyrolytic carbon $(\mathrm{PyC})$ and boron nitride $(\mathrm{BN})$ are the most commonly used interphase for CFCMCs [8], as their moderate shear strength can activate various toughening mechanisms, including crack arrest/deflection/branching, fiber/matrix debonding, and fiber pull-out. Various research has shown that an elaborated interphase is quite necessary to obtain CFCMCs with both high strength and high toughness, as it can induce crack deflection along the fiber surface without degrading the stress-bearing capability of the fiber $[9,10]$. The mechanical role of the interphase in the mechanical behavior of the composites is demonstrated to be closely related with its thickness [11-13], crystallinity [14,15], and sublayer sequence [16-18]. In terms of mechanics, the residual stress in the interphase may also play an important role as it can redistribute the stress within the composites and thus regulate the overall mechanical behavior. However, the relationship between the residual stress and the mechanical behavior is still not well understood.

For fiber-reinforced composites, residual stress almost inevitably exists in the interphase, considering the discontinuity of chemical composition and the mismatch of thermal expansion existing between the interphase with other adjacent constituents. Research has shown that interfacial residual stress in $\mathrm{SiC}$ fiber-reinforced $\mathrm{Ni}-\mathrm{Cr}-\mathrm{Al}$ composites can be as high as $\sim 1.9 \mathrm{GPa}$ and found that vacuum heat treatment can reduce the residual stress [19]. Moreover, the interfacial residual stress is demonstrated to be responsible for the premature formation of cracks in the composites [20-22]. $\mathrm{SiC}_{\mathrm{f}} / \mathrm{SiC}$ (continuous $\mathrm{SiC}$ fiber-reinforced $\mathrm{SiC}$ matrix composites) is one of the most widely studied CFCMCs and residual stress in the composites has also received increasing attention recently. Research has shown that $\mathrm{SiC}_{\mathrm{f}} / \mathrm{SiC}$ prepared by silicon melt infiltration exhibits residual tensile stress as high as $\sim 1.45$ and $0.5-0.7 \mathrm{GPa}$ in the matrix and the fiber, respectively [23]. Moreover, the silicon phase of the composites shows heterogeneous residual stress, with compressive stress of $\sim 180 \mathrm{MPa}$ in the intra-tow silicon while $\sim 300 \mathrm{MPa}$ in the matrix silicon [24]. Although recently there is growing research investigating the residual stress in $\mathrm{SiC}_{\mathrm{f}} / \mathrm{SiC}$, to the best knowledge of the authors, the interfacial residual stress of the composites and its effects on the mechanical behavior have not been studied.

In this study, the interfacial residual stress of $\mathrm{SiC}_{\mathrm{f}} / \mathrm{SiC}$ composites prepared by nano-infiltration and transient eutectic-phase (NITE) method was investigated using a micro-Raman spectrometer. The effects of the residual stress on the mechanical properties and the fracture morphologies of the composites were revealed. Besides, the mechanisms of the mechanical and microstructural evolution under the residual stress were also proposed. This study can offer new insight for the relationship between the interfacial residual stress and the mechanical behavior of CFCMCs.

\section{Experimental}

\section{1 Material preparation}

The $\mathrm{SiC}_{\mathrm{f}} / \mathrm{SiC}$ composites were prepared by an NITE process. Firstly, continuous $\mathrm{SiC}$ fiber cloths (Cansas 3303, Fujian Leaoasia New Material Ltd., Quanzhou, China) were coated with BN interphase $(\sim 600 \mathrm{~nm}$ in thickness) via chemical vapor deposition (CVD) method using $\mathrm{BCl}_{3}-\mathrm{NH}_{3}-\mathrm{H}_{2}-\mathrm{N}_{2}$ as the source gases. Subsequently, the fiber cloths were impregnated with a SiC slurry, which mainly consisted of $\mathrm{SiC}$ powder $(\sim 0.7 \mu \mathrm{m}$; Weifang Kaihua Silicon Carbide Micropowder Ltd., Weifang, China), $5 \mathrm{wt} \%$ binder (polyvinyl butyral, PVB), and $10 \mathrm{wt} \%$ sintering additives $\left(\mathrm{SiO}_{2}-\mathrm{Al}_{2} \mathrm{O}_{3}-\mathrm{Y}_{2} \mathrm{O}_{3}\right)$. The impregnated fiber cloths were then cut and stacked to form $70 \mathrm{~mm} \times 70 \mathrm{~mm} \times 5 \mathrm{~mm}$ preforms. The preforms were solidified at $120{ }^{\circ} \mathrm{C}$ and then pyrolyzed at $900{ }^{\circ} \mathrm{C}$ in flowing $\mathrm{Ar}$ atmosphere. Finally, the pyrolyzed preforms were densified at $1500-1650{ }^{\circ} \mathrm{C}$ for $2 \mathrm{~h}$ under pressure of $20 \mathrm{MPa}$ to obtain $\mathrm{SiC}_{\mathrm{f}} / \mathrm{SiC}$ composites.

\section{2 Residual stress determination}

The principle for residual stress determination using Raman spectroscopy is that residual stress is linearly related to Raman shift $[25,26]$. The Raman spectrum of the interphase was characterized by a combined equipment of micro-Raman spectrometer (Renishaw InVia, $532 \mathrm{~nm}$ laser, $10 \mathrm{~mW}$, Blue Scientific Limited, Cambridge, UK) and atomic force microscope (AFM; 
SPA400/SPI3800N, Seiko Inc., Japan). Using a focused laser as the excitation source, the resolution of the micro-Raman spectrometer almost reaches $\sim 0.5 \mu \mathrm{m}$. This makes it feasible to selectively probe the interphase. As both chemical and mechanical factors can lead to Raman shift, extracting the Raman shift caused by mechanical factors is critical to measure the residual stress. To simplify the measurement, it is assumed that the interphase residual stress is totally originated from the matrix formation of the composites. Therefore, the effective Raman shift can be obtained as follows: (1) The Raman spectra of the as-coated interphase on the fiber are collected and the Raman shift $\Delta \lambda_{1}$ is measured; (2) the Raman spectra of the interphase in the as-fabricated composites are collected and the Raman shift $\Delta \lambda_{2}$ is measured; (3) the effective Raman shift $\Delta \lambda_{\mathrm{c}}$ can be calculated as $\Delta \lambda_{\mathrm{c}}=\Delta \lambda_{2}-\Delta \lambda_{1}$. Therefore, the $\Delta \lambda_{\mathrm{c}}$ is the Raman shift totally induced by the matrix formation of the composites. To eliminate the Raman shift caused by high temperature, the as-coated interphases were also heat-treated at the same temperatures as the matrix fabrication. The characteristic peak at $1365 \mathrm{~cm}^{-1}$ is used as the reference stress-free peak for the interphase. This peak corresponds to the $E_{2 \mathrm{~g}}$ mode peak and is strongly dependent on the crystallographic structure of BN. A slight variation of crystallographic parameters can lead to significant shift of $E_{2 \mathrm{~g}}$ mode peak. Therefore, peak shifts $(\Delta \lambda)$ relative to $1365 \mathrm{~cm}^{-1}$ are used to calculate the interfacial residual stress $\sigma_{\mathrm{r}}$ based on the linear formula $\sigma_{\mathrm{r}}=C \times \Delta \lambda$.

\section{3 Mechanical test and microstructure characterization}

To investigate the effects of interfacial residual stress on the mechanical behavior of the composites, tensile tests were performed on the composites with a mechanical testing machine (DDL20, Changchun Research Institute for Mechanical Science Co., Ltd., Changchun, China) following standard ASTM C1275. The tensile span is $45 \mathrm{~mm}$ and the loading rate is 0.5 $\mathrm{mm} / \mathrm{min}$. For each group of the composites, at least five samples were tested and the reported mechanical strengths were the averaged values. Cross-sectional and fracture morphologies of the composites were observed using an SU8220 field emission scanning electron microscope (Hitachi, Tokyo, Japan). Topographic images of the as-coated interphases were recorded with an atomic force microscope (AFM; SPA400/SPI3800N, Seiko Inc., Japan) operated in an amplitude-modulation mode using $\mathrm{Si}$ as the cantilever (Micro Masch, NSC12-B, Estonia). The surficial roughness of the interphases was calculated statistically based on the topographic height of the interphase using Image Analysis software. Furthermore, the shear modulus of the interphases was measured according to the force/ distance curves obtained from AFM probe (DerjaguinMuller-Toporov, DMT model).

\section{Results and discussion}

For multiple-phase ceramic composites fabricated at high temperatures, residual stress in the constituents evolves due to the mismatch of thermal expansion. Presuming that $\mathrm{SiC}_{\mathrm{f}} / \mathrm{SiC}$ composites are an assembly of uniformly distributed $\mathrm{SiC}$ fiber, $\mathrm{SiC}$ matrix, and $\mathrm{BN}$ interphase existing between the fiber and the matrix, then the interfacial residual stress can be calculated based on the following classical equations $[27,28]$ :

$$
\begin{aligned}
& \sigma_{\mathrm{i}-\mathrm{f}}=-\frac{\left(\Delta \alpha_{\mathrm{i}}-\Delta \alpha_{\mathrm{f}}\right) \cdot \Delta T}{\left[\frac{0.5\left(1+v_{\mathrm{i}(T)}\right)+V_{\mathrm{f}}\left(1-2 v_{\mathrm{i}(T)}\right)}{E_{\mathrm{i}(T)}\left(1-V_{\mathrm{f}}\right)}+\frac{1-2 v_{\mathrm{f}(T)}}{E_{\mathrm{f}(T)}}\right]} \\
& \sigma_{\mathrm{i}-\mathrm{m}}=-\frac{\left(\alpha_{\mathrm{i}}-\alpha_{\mathrm{m}}\right) \cdot \Delta T}{\left[\frac{0.5\left(1+v_{\mathrm{i}(T)}\right)+V_{\mathrm{m}}\left(1-2 v_{\mathrm{i}(T)}\right)}{E_{\mathrm{i}(T)}\left(1-V_{\mathrm{m}}\right)}+\frac{1-2 v_{\mathrm{m}(T)}}{E_{\mathrm{m}(T)}}\right]}
\end{aligned}
$$

where $\sigma_{\mathrm{i}-\mathrm{f}}$ is the residual stress caused by the thermal mismatch between the interphase (i) and the fiber (f), and $\sigma_{\mathrm{i}-\mathrm{m}}$ is the residual stress caused by the thermal mismatch between the interphase (i) and the matrix (m). Both the residual stresses can be expressed as a function of the difference between processing and ambient temperature $(\Delta T)$, thermal expansion coefficient $(\alpha)$, elastic modulus $(E)$, Poisson's ratio $(v)$, and the volume fraction $(V)$ of the constituents. Then the interfacial residual stress $\left(\sigma_{\mathrm{r}}\right)$ can be calculated as a weighted sum of $\sigma_{\mathrm{i}-\mathrm{f}}$ and $\sigma_{\mathrm{i}-\mathrm{m}}$ based on the volume fraction of the constituents:

$$
\sigma_{\mathrm{r}}=\frac{1}{V_{\mathrm{f}}+V_{\mathrm{m}}}\left(V_{\mathrm{f}} \sigma_{\mathrm{i}-\mathrm{f}}+V_{\mathrm{m}} \sigma_{\mathrm{i}-\mathrm{m}}\right)
$$

Substituting the thermo-mechanical parameters of the constituents into the above equations (most of the parameters are drawn from published literature and summarized in Table 1 ), then $\sigma_{\mathrm{i}-\mathrm{f}}, \sigma_{\mathrm{i}-\mathrm{m}}$, and $\sigma_{\mathrm{r}}$ can be expressed as below:

$$
\sigma_{\mathrm{i}-\mathrm{f}}=3.4798 \times 10^{-2} \Delta T(\mathrm{MPa})
$$




$$
\begin{gathered}
\sigma_{\mathrm{i}-\mathrm{m}}=1.8975 \times 10^{-2} \Delta T(\mathrm{MPa}) \\
\sigma_{\mathrm{r}}=2.4934 \times 10^{-2} \Delta T(\mathrm{MPa})
\end{gathered}
$$

Then relationship of $\sigma_{\mathrm{i}-\mathrm{f}}, \sigma_{\mathrm{i}-\mathrm{m}}$, and $\sigma_{\mathrm{r}}$ versus processing temperature can be plotted as Fig. 1. All the residual stresses linearly increase with the temperature, and the $\sigma_{\mathrm{i}-\mathrm{f}}$ is a little higher than $\sigma_{\mathrm{i}-\mathrm{m}}$, indicating that the fiber accounts more than the matrix in the formation of interfacial residual stress. As the $\mathrm{SiC}_{\mathrm{f}} / \mathrm{SiC}$ composites were prepared at $1500-1650{ }^{\circ} \mathrm{C}$, the interfacial residual stress $\left(\sigma_{\mathrm{r}}\right)$ is $\sim 40 \mathrm{MPa}$. However, as the residual stress calculation only considers the thermal expansion mismatch, the actual residual stress may be higher due to the pressure applied in the preparation process.

Raman is an effective technique to measure residual stress by correlating the residual stress with Raman peak shift. As the composites were prepared at high temperatures, in order to assure that the measured Raman shift is resulted from residual stress, not from heat-induced microstructure evolution, two strategies are adopted to calibrate the measurement. First, the microstructures of the interphase at RT-1650 ${ }^{\circ} \mathrm{C}$ are contrasted so as to eliminate the possibility that microstructural factors dominate the Raman shift. Second, the Raman shift of the interphase after the

Table 1 Thermal and mechanical properties of $\mathrm{BN}$ interphase, SiC fiber, and $\mathrm{SiC}$ matrix

\begin{tabular}{ccccc}
\hline & $\begin{array}{c}\text { Volume } \\
\text { fraction }\end{array}$ & $\begin{array}{c}\text { Thermal expansion } \\
\text { coefficient } \\
\left(10^{-6}{ }^{\circ} \mathrm{C}^{-1}\right)\end{array}$ & $\begin{array}{c}\text { Elastic } \\
\text { modulus } \\
(\mathrm{GPa})\end{array}$ & $\begin{array}{c}\text { Poisson's } \\
\text { ratio }\end{array}$ \\
\hline BN interphase & 0.07 & $2.7[29]$ & $24[30]$ & $0.13[31]$ \\
$\mathrm{SiC}$ fiber & 0.35 & $4.6[32]$ & $280[33]$ & $0.25[33]$ \\
$\mathrm{SiC}$ marix & 0.58 & $4.6[32]$ & $400[33]$ & $0.20[33]$ \\
\hline
\end{tabular}

Note: the volume fraction was estimated based on weight variation during the preparation of the composites.

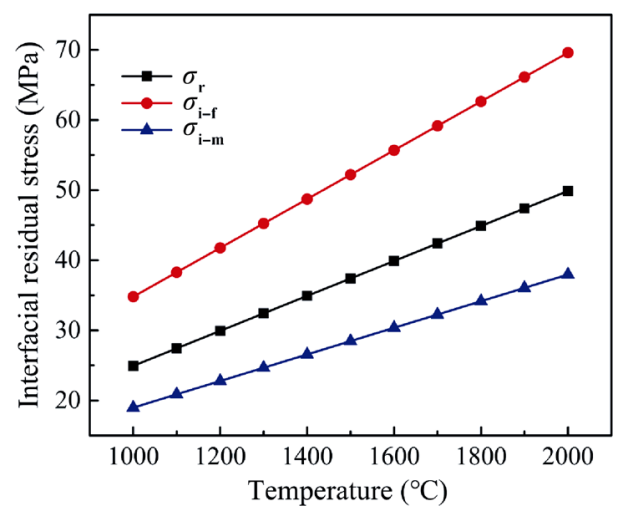

Fig. 1 Interfacial residual stress of $\mathrm{SiC}_{\mathrm{f}} / \mathrm{SiC}$ calculated from thermal expansion mismatch. matrix formation is calibrated by that before the matrix formation, so the calibrated Raman shift can be considered to be totally induced by the residual stress generated during the matrix formation.

The microstructure images (Figs. 2(a) and 2(b)) indicate that the as-coated interphase is uniformly coated on the fiber surface. The surficial morphology of the interphase is granular, with a granule size of $\sim 500 \mathrm{~nm}$. The cross-sectional morphology of the interphase ( $\sim 600 \mathrm{~nm}$ in thickness) is characteristic of layered structure and the sublayer is $\sim 20 \mathrm{~nm}$ in thickness. As the interphase is heat-treated at 1550 and $1650{ }^{\circ} \mathrm{C}$, the surficial granule size $(\sim 500 \mathrm{~nm})$ almost remains the same with that of the untreated interphase (Figs. 2(c)-2(e)), indicating that the interphase remains thermally stable during the high-temperature processing. This can be further confirmed by the statistical results of the surficial roughness $\left(R_{\mathrm{a}}\right)$, as shown in Figs. 2(f)2(h). The $R_{\mathrm{a}}$ values of the interphase surfaces (corresponding to green line in Figs. 2(c)-2(e)) are 21-22 $\mathrm{nm}$. The thermally stable interphase makes Raman spectroscopy a feasible tool to measure the residual stress of $\mathrm{SiC}_{\mathrm{f}} / \mathrm{SiC}$ composites that fabricated at high temperatures.

The cross-sectional morphologies (Figs. 3(a) and 3(b)) of the as-received $\mathrm{SiC}_{\mathrm{f}} / \mathrm{SiC}$ composites (fabricated at $1500{ }^{\circ} \mathrm{C}$ ) show that the reinforcing fibers are surrounded uniformly by a dense $\mathrm{SiC}$ matrix. The $\mathrm{BN}$ interphase remains intact and bonds tightly with the fibers and the matrix. Considering their different thermal expansion coefficients, there must be significant residual stress in the interphase. To investigate the variation of residual stress with the fabrication temperature, four groups of $\mathrm{SiC}_{\mathrm{f}} / \mathrm{SiC}$ composites fabricated at 1500, 1550, 1600, and $1650{ }^{\circ} \mathrm{C}$ are used for the determination of residual stress. The Raman spectra of the interphases as-coated on the fiber surface and within the as-fabricated composites are shown in Fig. 3(c). For the purpose of calibration, the as-coated interphases were heat-treated at the same temperatures as the matrix fabrication. All the spectra show a sharp and strong peak at $\sim 1365 \mathrm{~cm}^{-1}$, which corresponds to the in-plane vibration of $\mathrm{BN}$ phase $[34,35]$. The in-plane vibration has proved to be highly sensitive to the residual stress in the phase, and a certain amount of vibration peak shift represents a proportional residual stress in the phase [36]. The Raman results show that all the vibration peaks of the interphases show a negative shift relative to the characteristic peak position of $\mathrm{BN}$ phase at stress-free 

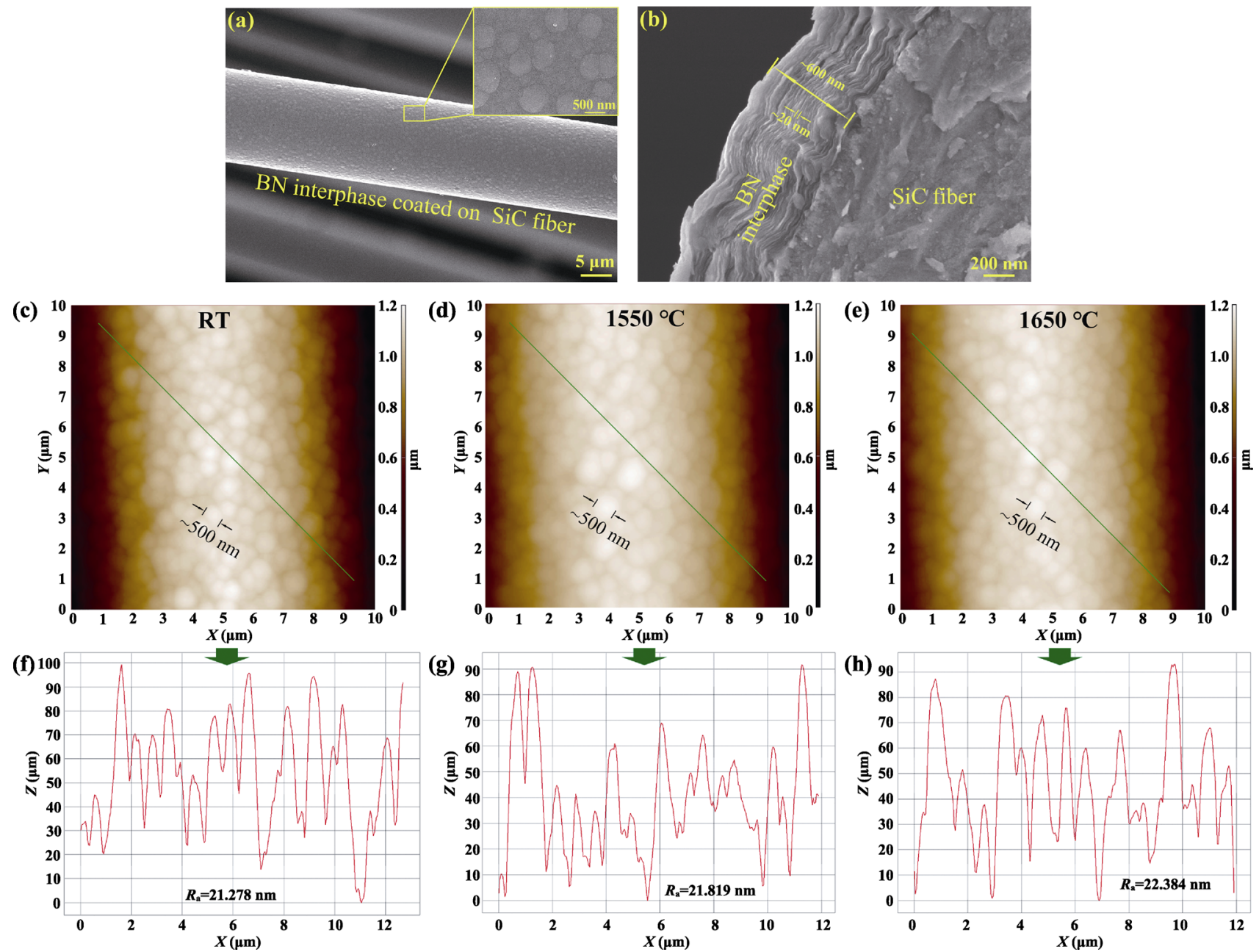

Fig. 2 (a, b) SEM images of as-coated BN interphase on SiC fiber surface, (c-e) AFM images of the interphase at RT, 1550, and $1650{ }^{\circ} \mathrm{C}$, and $(\mathrm{f}-\mathrm{h})$ surficial roughness of the interphase.
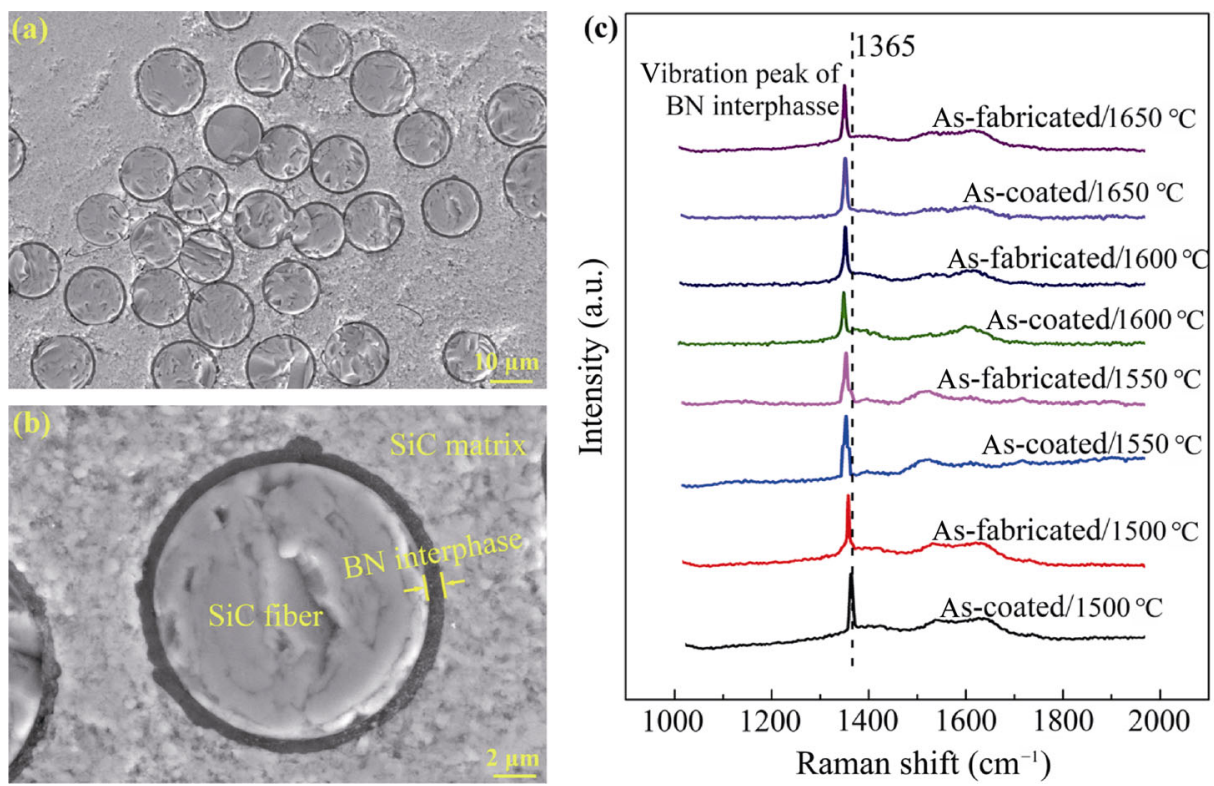

Fig. 3 (a, b) SEM images of the as-fabricated $\mathrm{SiC}_{\mathrm{f}} / \mathrm{SiC}$ and (c) selected-area Raman spectra of the BN interphases as-coated on $\mathrm{SiC}$ fiber surface and within the $\mathrm{SiC}_{\mathrm{f}} / \mathrm{SiC}$. 
state $\left(\sim 1365 \mathrm{~cm}^{-1}\right)$. As some chemical factors may also cause Raman shift, the Raman shift must be calibrated to determinate the residual stress.

The calibration of Raman shift should consider two chemical factors. First, the CVD-derived BN interphase has some distinct microstructure features (Figs. 2(a) and 2(b)) compared with standard BN phase. Second, the high-temperature conditions of the matrix formation may induce atom diffusion/rearrangement in the interphase. Both these two factors can contribute to Raman shift. By subjecting the as-coated interphase to heat-treatment at the same temperatures as that of the matrix fabrication, the Raman shifts caused by the above factors are approximately the same for the as-coated interphase and the interphase within the composites. Therefore, the calibrated Raman shift $\left(\Delta \lambda_{\mathrm{c}}\right)$ can be obtained by subtracting the Raman shift of the as-coated interphase from that of the interphase in the composites (Fig. 4):

$$
\Delta \lambda_{\mathrm{c}}=\Delta \lambda_{2}-\Delta \lambda_{1}
$$

where $\Delta \lambda_{1}$ and $\Delta \lambda_{2}$ denote the Raman shifts of as-coated interphase and the interphase within the composites, respectively. Then the interfacial residual stress $\left(\sigma_{\mathrm{r}}\right)$ in the composites can be calculated as below:

$$
\sigma_{\mathrm{r}}=C \times \Delta \lambda_{\mathrm{c}}
$$

where $C$ is the conversion factor of Raman shift to residual stress. For $\mathrm{BN}$ phase, $C$ is a constant of -0.2950 [36-38]. The negative valve of $C$ indicates that a negative Raman shift in $\mathrm{BN}$ phase represents a positive $\sigma_{\mathrm{r}}$ value, i.e., tensile residual stress generated in the phase.

The variations of the Raman shift $\left(\Delta \lambda_{\mathrm{c}}\right)$ and the interfacial residual stress $\left(\sigma_{\mathrm{r}}\right)$ versus the fabrication

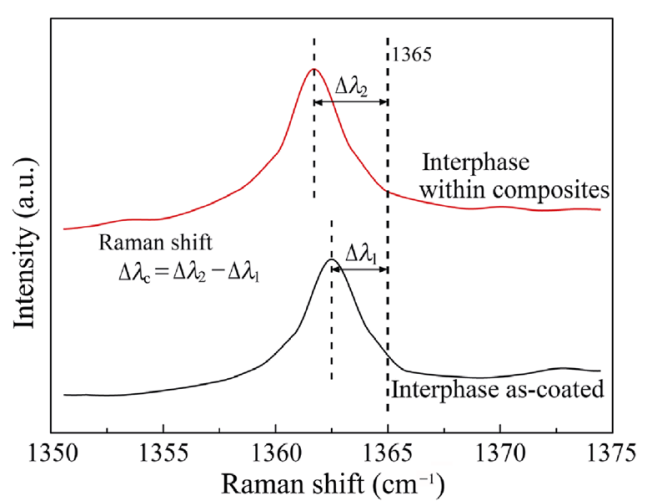

Fig. 4 Schematic of calibrating Raman shift in the BN interphase.

temperature are shown in Fig. 5(a). As the fabrication temperature increases from 1500 to $1650{ }^{\circ} \mathrm{C}$, the $\Delta \lambda_{\mathrm{c}}$ of the interphase decreases from -0.09 to $-0.28 \mathrm{~cm}^{-1}$. Correspondingly, the $\sigma_{\mathrm{r}}$ increases from 26.5 to 82.6 $\mathrm{MPa}$ in tension. Compared with the calculated results based on thermal expansion mismatch (Fig. 1), the Raman-measured $\sigma_{\mathrm{r}}$ is significantly higher when the temperature exceeding $1600{ }^{\circ} \mathrm{C}$. Especially at $1650{ }^{\circ} \mathrm{C}$, the measured $\sigma_{\mathrm{r}}$ is almost twice the calculated $\sigma_{\mathrm{r}}$. As mentioned before, the calculated $\sigma_{\mathrm{r}}$ is obtained based on the thermal expansion mismatch without considering the pressure applied during the fabrication; therefore, the calculated $\sigma_{\mathrm{r}}$ should be underestimated. As both the fiber and the matrix have a higher thermal expansion coefficient than the interphase (Table 1), the formers expand more than the latter during the composite fabrication. Especially along the fiber axial direction, the expansion of the fibers is rather remarkable due to their extremely high length-diameter ratio (Fig. 5(b)). This subjects the interphase to residual tensile stress along the fiber axial direction.
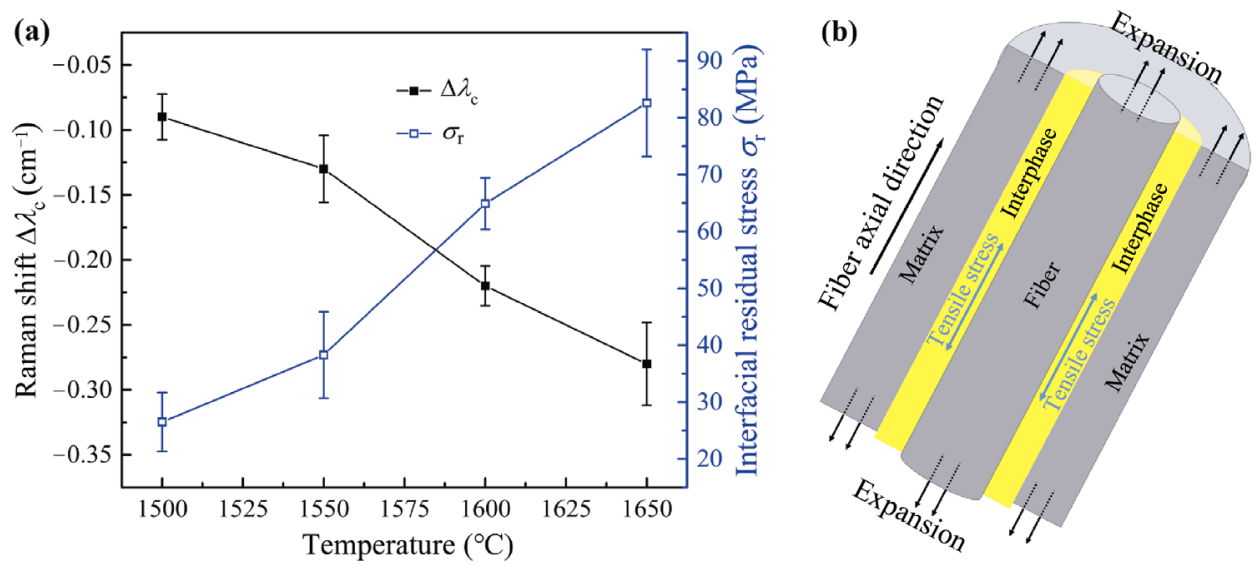

Fig. 5 (a) Raman shift and interfacial residual stress as a function of temperature and (b) schematic of interfacial residual stress in the $\mathrm{SiC}_{\mathrm{f}} / \mathrm{SiC}$. 
For $\mathrm{SiC}_{\mathrm{f}} / \mathrm{SiC}$ composites, the interphase decides the mechanical behavior by tailoring the bonding strength between the fiber and the matrix. The residual stress in the interphase may change the bonding strength and thus exerts significant influence on the overall mechanical properties of the composites. In order to investigate the effects of residual stress on the mechanical properties, tensile mechanical tests were performed on the composites with various residual stresses in the interphase. The tensile stress-strain curves are shown in Fig. 6 and the mechanical properties are summarized in Table 2. All the composites show non-brittle fracture behaviors, with tensile strength $\sim 200 \mathrm{MPa}$ and tensile strain $\sim 0.40 \%$. As the interfacial residual stress increases from 26.5 to $64.9 \mathrm{MPa}$, the tensile strength increases from 171 to $238 \mathrm{MPa}$, and the tensile strain from $0.33 \%$ to $0.45 \%$. However, as the residual stress reaches to 82.6 MPa, both the tensile strength and the tensile strain decrease significantly, declining to $184 \mathrm{MPa}$ and $0.36 \%$, respectively. The variation of mechanical properties indicates that the interfacial residual stress has significant effects on the mechanical behavior of the composites. The residual stress may induce different fiber/matrix debonding modes and thus contribute to the different mechanical properties. The effects of the residual stress can be further confirmed by the fracture microstructures of the composites.

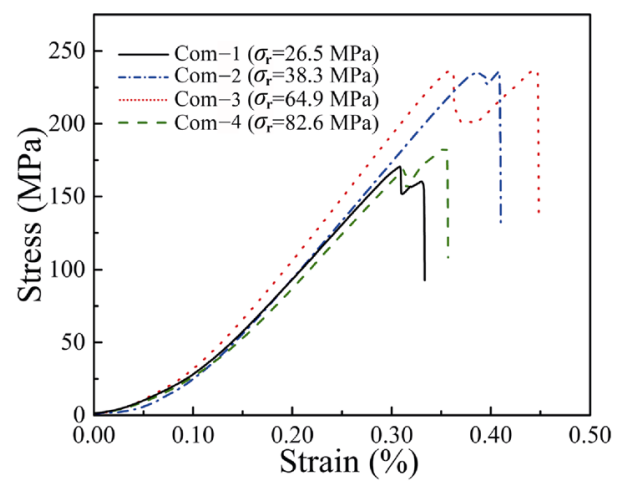

Fig. 6 Tensile stress-strain curves of the $\mathrm{SiC}_{\mathrm{f}} / \mathrm{SiC}$ with various interfacial residual stresses.

Table 2 Mechanical properties of the $\mathrm{SiC}_{\mathrm{f}} / \mathrm{SiC}$ with various interfacial residual stresses

\begin{tabular}{cccc}
\hline Sample & $\begin{array}{c}\text { Interfacial residual } \\
\text { stress } \sigma_{\mathrm{r}}(\mathrm{MPa})\end{array}$ & $\begin{array}{c}\text { Tensile strain } \\
(\%)\end{array}$ & $\begin{array}{c}\text { Tensile strength } \\
(\mathrm{MPa})\end{array}$ \\
\hline Com-1 & $26.5 \pm 5.2$ & $0.33 \pm 0.03$ & $171 \pm 13$ \\
Com-2 & $38.3 \pm 7.6$ & $0.41 \pm 0.05$ & $236 \pm 15$ \\
Com-3 & $64.9 \pm 4.5$ & $0.45 \pm 0.06$ & $238 \pm 21$ \\
Com-4 & $82.6 \pm 9.4$ & $0.36 \pm 0.03$ & $184 \pm 11$ \\
\hline
\end{tabular}

The fracture surfaces of the composites show that with the interfacial residual stress increasing from 26.5 to $64.9 \mathrm{MPa}$ the composites show prolonging length of fiber pull-out (Figs. 7(a), 7(c), and 7(e)), which coincides with the increasing tensile strain in the composites (Table 2). This may indicate that the increasing residual stress can facilitate the fiber/matrix debonding. For fiber-reinforced composites, different fiber/matrix debonding modes can lead to rather different fracture behaviors. In terms of where debonding occurs, the debonding of $\mathrm{SiC}_{\mathrm{f}} / \mathrm{SiC}$ can be divided into $\mathrm{i} / \mathrm{f}$ type and $\mathrm{i} / \mathrm{i}$ type. For $\mathrm{i} / \mathrm{f}$ type, the debonding occurs at interphase/fiber interface, while for $\mathrm{i} / \mathrm{i}$ type, the debonding occurs within the interphase. As the residual stress increases from 26.5 to $64.9 \mathrm{MPa}$, the debonding mode transforms from $\mathrm{i} / \mathrm{f}$ type to $\mathrm{i} / \mathrm{i}$ type (Figs. $7(\mathrm{~b})$, $7(\mathrm{~d})$, and 7(f)). As the residual stress further increases to $82.6 \mathrm{MPa}$, the length of fiber pull-out decreases significantly (Fig. 7(g)). Although the debonding is still an $\mathrm{i} / \mathrm{i}$ type, the interphase is delaminated drastically and peeled from the fiber (Fig. 7(h)). This indicates low shear strength of the interphase and thus low bonding strength of fiber/matrix. The low bonding strength can prevent stress transferring from the matrix to the fibers, thus inhibiting the reinforcing effect of the fibers. Therefore, the composites (Com-4) show a significant decrease in tensile strength and tensile strain compared with Com-2 and Com-3.

In general, fiber/matrix debonding mode of fiberreinforced composites is mainly dependent on the shear characteristics of interphase. The residual stress in the interphase may change the shear characteristics, thus leading to the different debonding modes in the composites. The effects of the residual stress on the shear characteristics can be shown in Fig. 8. Due to the different thermal/mechanical properties between the fiber and matrix, the interfacial residual stress is inhomogeneous across the thickness of the interphase, and the residual stress close to the fiber is higher than that close to the matrix (which is deduced by higher $\sigma_{\mathrm{i}-\mathrm{f}}$ than $\sigma_{\mathrm{i}-\mathrm{m}}$ in Fig. 1). From the view of mechanics, the inhomogeneous residual stress can be equivalent to residual shear stress across the thickness of the interphase (Fig. 8(a)). The residual shear stress can facilitate sublayer shear slipping in the interphase, and thus weaken the shear strength of the interphase. To quantitatively investigate the shear property of the interphase, indentation testing was performed on the interphase using an AFM probe. During the indentation, 


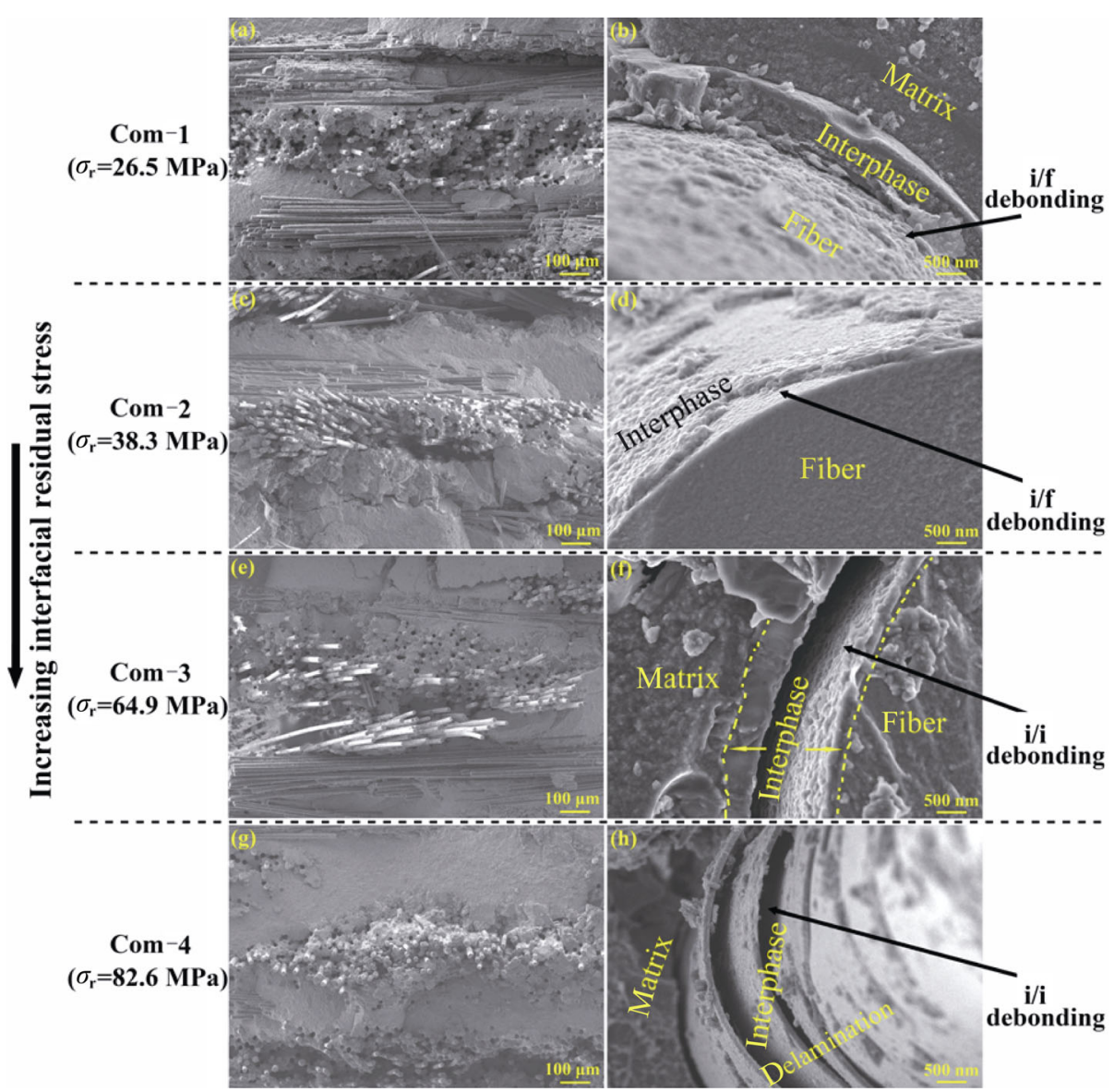

Fig. $7 \mathrm{SEM}$ images of the fracture surfaces of $\mathrm{SiC}_{\mathrm{f}} / \mathrm{SiC}$ with various interfacial residual stresses.
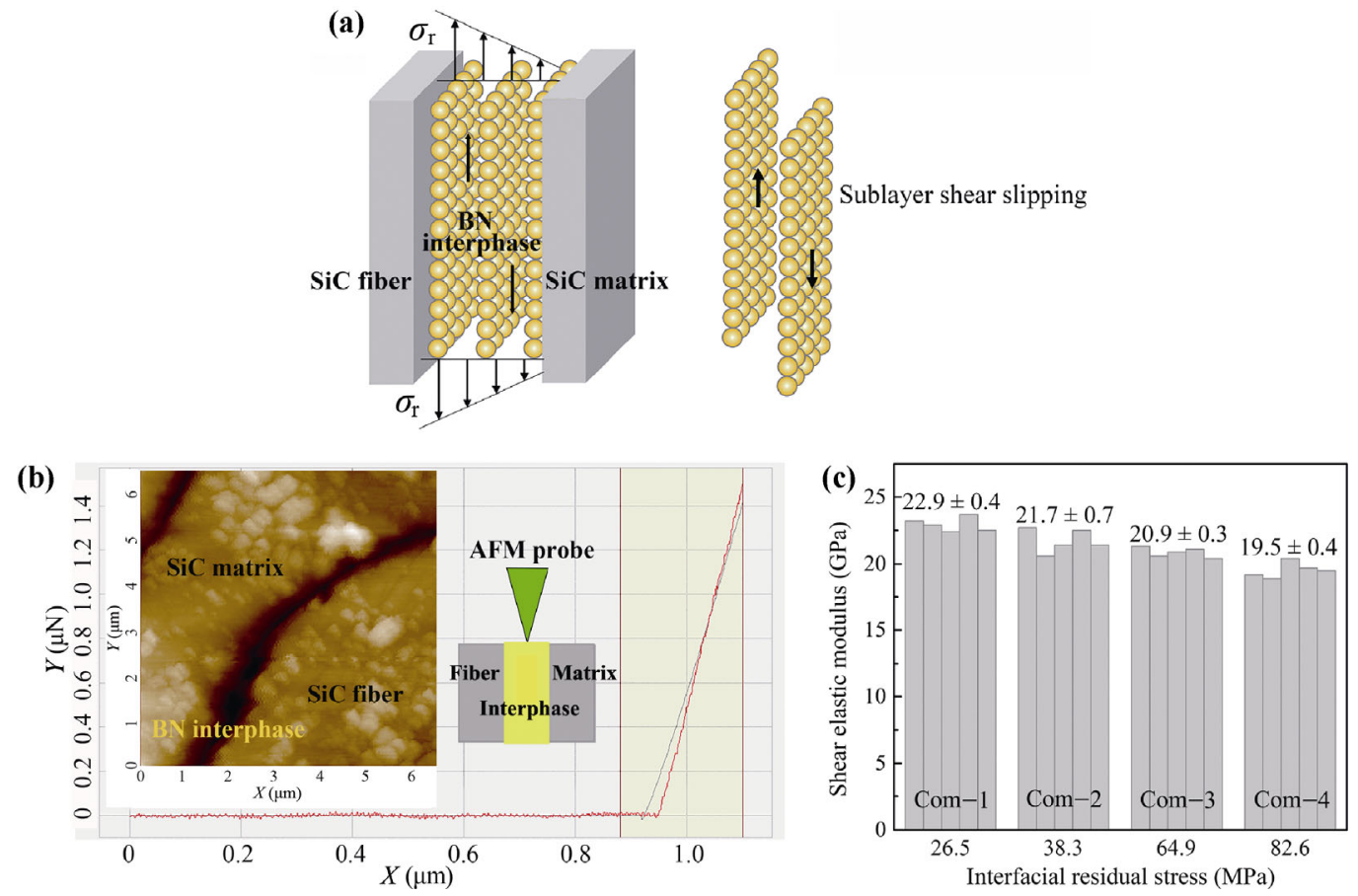

Fig. 8 Effects of the interfacial residual stress on the shear modulus of the BN interphase: (a) inhomogeneous distribution of the interfacial residual stress, (b) indentation testing on the interphase using an AFM probe, and (c) shear modulus of the interphase versus the interfacial residual stress. 


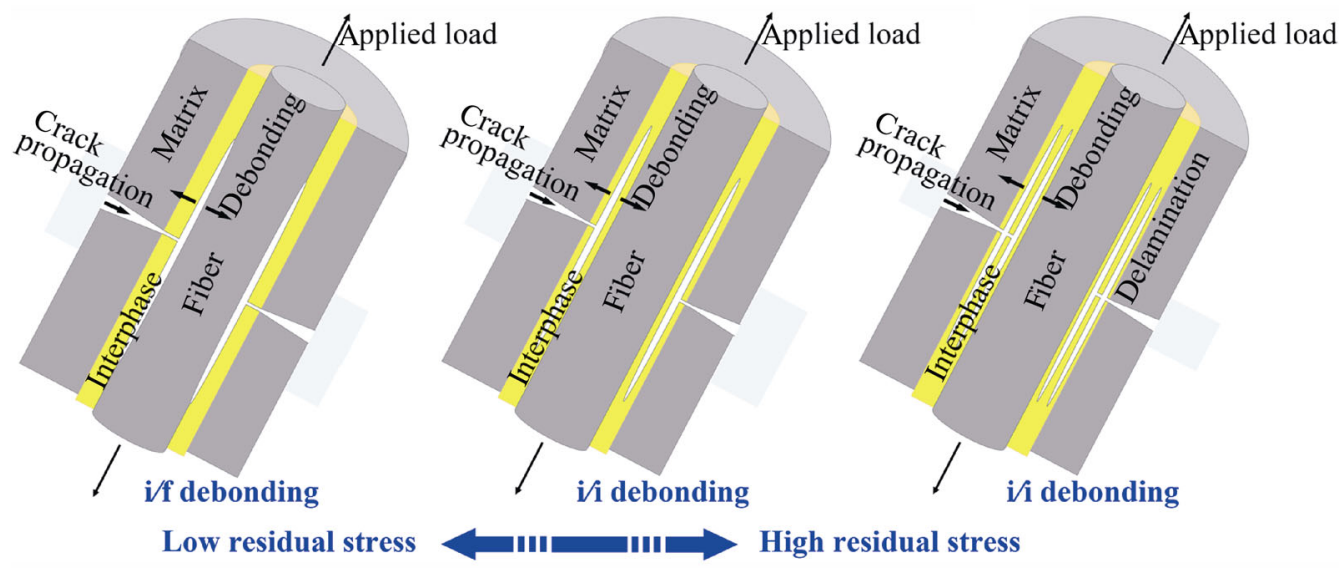

Fig. 9 Schematic of fiber/matrix debonding transformation in $\mathrm{SiC}_{\mathrm{f}} / \mathrm{SiC}$ under increasing interfacial residual stress.

the force vs. distance curve is recorded and then the shear modulus of the interphase is obtained based on the curve slope (Fig. 8(b)). As the interfacial residual stress increases from 26.5 to $82.6 \mathrm{MPa}$, the shear modulus of the interphase decreases from 22.9 to 19.5 GPa (Fig. 8(c)). This confirms that the residual stress can degrade the shear strength of the interphase and thus facilitate sublayer slipping in the interphase. At low residual stress, the moderate sublayer slipping in the interphase can strengthen the reinforcing effect of fiber by promoting fiber/matrix debonding, which leads to improvement of mechanical properties. However, high residual stress can lead to immoderate sublayer slipping. The immoderate sublayer slipping can lead to significant delamination in the interphase, which degrades the reinforcing effect of fiber and thus worsens the mechanical properties of the composites.

Therefore, the effects of interfacial residual stress on the mechanical behavior of the composites can be illustrated in Fig. 9. The residual stress can lead to fiber/matrix debonding within the interphase by inducing sublayer slipping in the interphase. As the residual stress is low, the debonding preferentially occurs at interphase/fiber interface. However, increasing the residual stress can lead to $\mathrm{i} / \mathrm{i}$ debonding, where the debonding occurs within the interphase. Benefiting from the enhanced fiber pull-out of $\mathrm{i} / \mathrm{i}$ debonding, both mechanical strength and strain of the composites are improved. Furthermore, with the residual stress increasing up to a certain threshold, the interphase is delaminated presumably due to its immoderate sublayer slipping. The delaminated interphase can suppress stress transferring from the matrix to the fiber, resulting in deteriorating mechanical properties. Actually, the effects of the residual stress on the mechanical behavior should consider the intrinsic characteristics of the composites, such as chemical composition, fiber fabric, and preparation condition. Therefore, the overall understanding of residual stress in the composites still needs more researches. Nevertheless, this study promotes the research by providing a method for determining the residual stress in the interphase and revealing its effects on the mechanical behavior of the composites.

\section{Conclusions}

In present study, the interfacial residual stress of $\mathrm{SiC}$ fiber-reinforced $\mathrm{SiC}$ matrix $\left(\mathrm{SiC}_{\mathrm{f}} / \mathrm{SiC}\right)$ composites was investigated using a micro-Raman spectrometer. The residual stress was measured based on the Raman shift of the BN interphase. It was found that the residual stress increases from 26.5 to $82.6 \mathrm{MPa}$ as the fabrication temperature of the composites rises from 1500 to $1650{ }^{\circ} \mathrm{C}$. The residual stress is tensile with direction parallel to the fiber axis, and found to exert significant influence on the mechanical properties of the composites. The increasing residual stress can improve the tensile strength of the composites from 171 to $238 \mathrm{MPa}$. The transformation of fiber/matrix debonding from $\mathrm{i} / \mathrm{f}$ type to $\mathrm{i} / \mathrm{i}$ type induced by the residual stress should be responsible for the improvement of the mechanical properties. However, with the residual stress increasing up to $82.6 \mathrm{MPa}$, the mechanical properties of the composites degrade remarkably due to the delamination of the interphase. This work provides a feasible alternative for determination of interfacial residual stress in fiber-reinforced ceramic composites, and offers new insight for the relationship between the residual stress and the mechanical behavior of the composites. 


\section{Acknowledgements}

Authors appreciate the financial support of the research grant from the National Natural Science Foundation of China (No. 51902328), the research grant from the Science and Technology Commission of Shanghai Municipality (No. 19ZR1464700), the research grant from the Innovation Academy for Light-duty Gas Turbine, CAS (No. CXYJJ20QN-09), the research grant from the Chinese Academy of Sciences (No. QYZDY-SSW-JSC031), and the research grant from the Key Deployment Projects of the Chinese Academy of Sciences (No. ZDRW-CN-2019-01).

\section{References}

[1] Di Carlo JA, Yun HM, Morscher GN, et al. SiC/SiC composites for $1200{ }^{\circ} \mathrm{C}$ and above. In Handbook of Ceramic Composites. Boston, MA, USA: Springer US, 2005: 77-98.

[2] Zok FW. Ceramic-matrix composites enable revolutionary gains in turbine engine efficiency. Am Ceram Soc Bull 2016, 95: 22-28.

[3] Naslain R. Materials design and processing of high temperature ceramic matrix composites: State of the art and future trends. Adv Compos Mater 1999, 8: 3-16.

[4] Naslain R. Design, preparation and properties of non-oxide CMCs for application in engines and nuclear reactors: An overview. Compos Sci Technol 2004, 64: 155-170.

[5] Steibel J. Ceramic matrix composites taking flight at GE Aviation. Am Ceram Soc Bull 2019, 98: 30-33.

[6] Carrère N, Martin E, Lamon J. The influence of the interphase and associated interfaces on the deflection of matrix cracks in ceramic matrix composites. Compos $A$ : Appl Sci Manuf 2000, 31: 1179-1190.

[7] Naslain RR. The design of the fibre-matrix interfacial zone in ceramic matrix composites. Compos A: Appl Sci Manuf 1998, 29: 1145-1155.

[8] Yang B, Zhou XG, Chai YX. Mechanical properties of $\mathrm{SiC}_{\mathrm{f}} / \mathrm{SiC}$ composites with $\mathrm{PyC}$ and the $\mathrm{BN}$ interface. Ceram Int 2015, 41: 7185-7190.

[9] Kerans RJ, Hay RS, Parthasarathy TA, et al. Interface design for oxidation-resistant ceramic composites. $\mathrm{J} \mathrm{Am}$ Ceram Soc 2002, 85: 2599-2632.

[10] Yu HJ, Zhou XG, Zhang W, et al. Mechanical properties of 3D KD-I $\mathrm{SiC}_{\mathrm{f}} / \mathrm{SiC}$ composites with engineered fibre-matrix interfaces. Compos Sci Technol 2011, 71: 699-704.

[11] Mei H, Bai QL, Sun YY, et al. The effect of heat treatment on the strength and toughness of carbon fiber/silicon carbide composites with different pyrolytic carbon interphase thicknesses. Carbon 2013, 57: 288-297.

[12] Nakazato N, Kishimoto H, Park JS. Appropriate thickness of pyrolytic carbon coating on $\mathrm{SiC}$ fiber reinforcement to secure reasonable quasi-ductility on NITE $\mathrm{SiC} / \mathrm{SiC}$ composites. Ceram Int 2018, 44: 19307-19313.
[13] Cao XY, Yin XW, Fan XM, et al. Effect of PyC interphase thickness on mechanical behaviors of $\mathrm{SiBC}$ matrix modified $\mathrm{C} / \mathrm{SiC}$ composites fabricated by reactive melt infiltration. Carbon 2014, 77: 886-895.

[14] Mei H, Li HQ, Bai QL, et al. Increasing the strength and toughness of a carbon fiber/silicon carbide composite by heat treatment. Carbon 2013, 54: 42-47.

[15] Buet E, Sauder C, Sornin D, et al. Influence of surface fibre properties and textural organization of a pyrocarbon interphase on the interfacial shear stress of $\mathrm{SiC} / \mathrm{SiC}$ minicomposites reinforced with Hi-Nicalon $\mathrm{S}$ and Tyranno SA3 fibres. J Eur Ceram Soc 2014, 34: 179-188.

[16] Rebillat F, Lamon J, Naslain R, et al. Properties of multilayered interphases in $\mathrm{SiC} / \mathrm{SiC}$ chemical-vaporinfiltrated composites with "weak" and "strong" interfaces. J Am Ceram Soc 1998, 81: 2315-2326.

[17] Yang W, Kohyama A, Katoh Y, et al. Effect of carbon and silicon carbide/carbon interlayers on the mechanical behavior of tyranno-SA-fiber-reinforced silicon carbidematrix composites. J Am Ceram Soc 2003, 86: 851-856.

[18] Mainzer B, Jemmali R, Watermeyer P, et al. Development of damage-tolerant ceramic matrix composites $(\mathrm{SiC} / \mathrm{SiC})$ using $\mathrm{Si}-\mathrm{BN} / \mathrm{SiC} / \mathrm{PyC}$ fiber coatings and LSI processing. $J$ Ceram Sci Tech 2017, 8:113-120.

[19] Niu XX, Zhang HQ, Pei ZL, et al. Measurement of interfacial residual stress in $\mathrm{SiC}$ fiber reinforced $\mathrm{Ni}-\mathrm{Cr}-\mathrm{Al}$ alloy composites by Raman spectroscopy. J Mater Sci Technol 2019, 35: 88-93.

[20] Xing YM, Tanaka Y, Kishimoto S, et al. Determining interfacial thermal residual stress in $\mathrm{SiC} / \mathrm{Ti}-15-3$ composites. Scripta Mater 2003, 48: 701-706.

[21] Chen H, Zeng FH, Li WJ, et al. Effect of interfacial residual thermal stress on the fracture behavior of $\mathrm{C}_{\mathrm{f}} / \mathrm{B}_{4} \mathrm{C}$ composites prepared by spark plasma sintering. Ceram Int 2020, 46: 4587-4594.

[22] Hsueh CH. Evaluation of interfacial shear strength, residual clamping stress and coefficient of friction for fiber-reinforced ceramic composites. Acta Metall Mater 1990, 38: 403-409.

[23] Kollins K, Przybyla C, Amer MS. Residual stress measurements in melt infiltrated $\mathrm{SiC} / \mathrm{SiC}$ ceramic matrix composites using Raman spectroscopy. J Eur Ceram Soc 2018, 38: 2784-2791.

[24] Knauf MW, Przybyla CP, Ritchey AJ, et al. Residual stress determination of silicon containing boron dopants in ceramic matrix composites. J Am Ceram Soc 2019, 102: 2820-2829.

[25] Amer MS. Raman Spectroscopy, Fullerenes, and Nanotechnology. Cambridge, UK: Royal Society of Chemistry, 2010.

[26] Gouadec G, Karlin S, Wu J, et al. Physical chemistry and mechanical imaging of ceramic-fibre-reinforced ceramicor metal-matrix composites. Compos Sci Technol 2001, 61: 383-388.

[27] Chawla KK. Processing of ceramic matrix composites. In Ceramic Matrix Composites. Boston, USA: Springer US, 2003: 107-138. 
[28] Jannotti P, Subhash G, Zheng J, et al. Measurement of microscale residual stresses in multi-phase ceramic composites using Raman spectroscopy. Acta Mater 2017, 129: 482-491.

[29] Paszkowicz W, Pelka JB, Knapp M, et al. Lattice parameters and anisotropic thermal expansion of hexagonal boron nitride in the 10-297.5 K temperature range. Appl Phys A 2002, 75: 431-435.

[30] Lipp A, Schwetz KA, Hunold K. Hexagonal boron nitride: Fabrication, properties and applications. J Eur Ceram Soc 1989, 5: 3-9.

[31] Bochko AV, Zaporozhets OI. Elastic constants and elasticity moduli of cubic and wurtzitic boron nitride. Powder Metall Met Ceram 1996, 34: 417-423.

[32] Pailler F, Lamon J. Micromechanics based model of fatigue/oxidation for ceramic matrix composites. Compos Sci Technol 2005, 65: 369-374.

[33] Guillaumat L, Lamon J. Probabilistic-statistical simulation of the non-linear mechanical behavior of a woven SiCSiC composite. Compos Sci Technol 1996, 56: 803-808.

[34] Ahmad AU, Liang HW, Ali S, et al. Cheap, reliable, reusable, thermally and chemically stable fluorinated hexagonal boron nitride nanosheets coated Au nanoparticles substrate for surface enhanced Raman spectroscopy. Sens Actuat B: Chem 2020, 304: 127394.

[35] Du M, Li XL, Wang AZ, et al. One-step exfoliation and fluorination of boron nitride nanosheets and a study of their magnetic properties. Angewandte Chemie Int Ed 2014, 53: 3645-3649.

[36] Fahy S. Erratum: Calculation of the strain-induced shifts in the infrared-absorption peaks of cubic boron nitride. Phys Rev B 1996, 53: 11884.

[37] Sanjurjo JA, López-Cruz E, Vogl P, et al. Dependence on volume of the phonon frequencies and the ir effective charges of several III-V semiconductors. Phys Rev B 1983, 28: 4579-4584.

[38] Erasmus RM, Comins JD, Fish ML, et al. Raman spectroscopy as a technique to characterize stress in diamond and cubic boron nitride. AIP Conf Proc 2000, 509: 1637-1644.

Open Access This article is licensed under a Creative Commons Attribution 4.0 International License, which permits use, sharing, adaptation, distribution and reproduction in any medium or format, as long as you give appropriate credit to the original author(s) and the source, provide a link to the Creative Commons licence, and indicate if changes were made.

The images or other third party material in this article are included in the article's Creative Commons licence, unless indicated otherwise in a credit line to the material. If material is not included in the article's Creative Commons licence and your intended use is not permitted by statutory regulation or exceeds the permitted use, you will need to obtain permission directly from the copyright holder.

To view a copy of this licence, visit http://creativecommons. org/licenses/by/4.0/. 